\title{
Thermal Microcautery, a Form of Peripheral Nerve Field Stimulation for Treatment of Painful Knee Osteoarthritis: Non-Randomized Controlled Trial
}

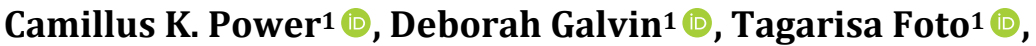 \\ Ahmed Abdelaal Ahmed Mahmoud ${ }^{2,3^{*}}$ (i), Nikolaos G. Kostopoulos 4 (i) \\ ${ }^{1}$ Department of Anesthesia, Critical Care \& Pain Medicine, Tallaght University Hospital, Dublin, Ireland \\ ${ }^{2}$ Department of Anaesthesia, Beni-Suef University Hospital, Beni-Suef, Egypt \\ ${ }^{3}$ Department of Anaesthesia, Birmingham Children's Hospital, Birmingham, UK \\ ${ }^{4}$ Holistic Health Centre, Athens, Greece \\ Email: camillus.power@tuh.ie, deborahgalvin@yahoo.ie, tagarisaf@gmail.com, ^dr.ahmedabdelaalmahmoud@gmail.com, \\ ngkostopoulos@gmail.com
}

How to cite this paper: Power, C.K., Galvin, D., Foto, T., Mahmoud, A.A.A. and Kostopoulos, N.G. (2019) Thermal Microcautery, a Form of Peripheral Nerve Field Stimulation for Treatment of Painful Knee Osteoarthritis: Non-Randomized Controlled Trial. Pain Studies and Treatment, 7, 33-54. https://doi.org/10.4236/pst.2019.73003

Received: July 14, 2019

Accepted: July 28, 2019

Published: July 31, 2019

Copyright $\odot 2019$ by author(s) and Scientific Research Publishing Inc. This work is licensed under the Creative Commons Attribution International License (CC BY 4.0).

http://creativecommons.org/licenses/by/4.0/

cc) (i) Open Access

\begin{abstract}
Background: Thermal Microcautery (TMC) is a form of peripheral nerve field stimulation and is a technique used in Traditional Indian Medicine (Agnikarma) to manage chronic pain. The aim was to asses TMC in painful knee osteoarthritis (PKO). Methods: A non-randomized controlled trial was employed. All PKO patients on a waiting list for knee replacement were offered PNFS-TMC. Patients in the intervention group received 4 sessions (2 weeks apart) of PNFS-TMC by a pin-point tip of a metal rod. The rod was heated over a flame for 5 minutes before being used to induce a single $1 \mathrm{~mm}$ second-degree burn over points of tenderness. The control group was selected from the same waiting list. The primary outcome was assessed by Visual Analogue Scale (VAS) scores. The secondary outcomes were changes in levels of physical day to day activity, sleep and analgesics. Results: 16 PNFS-TMC intervention group patients and 15 control group patients were subject to analysis. Baseline VAS score was higher in PNFS-TMC group [9 \pm 1.23 (95\% CI 8.38 - 9.61) versus $5.93 \pm 2.11(95 \%$ CI $4.81-7.06)$ in the control, $\mathrm{P}<$ 0.0001]. VAS scores after 8 weeks (i.e. 4 sessions) were lower in the PNFS-TMC group [4.64 $\pm 2.08(95 \%$ CI $3.57-5.72)$ versus $6.73 \pm 2.01(95 \%$ CI 5.61 - 7.85) respectively with $\mathrm{P}=0.0058$ ]. In the PNFS-TMC group, VAS score decreased from $9 \pm 1.23$ (95\% CI $8.38-9.61)$ at baseline to $4.64 \pm 2.08$ (95\% CI 3.57 - 5.72) after 4 sessions $(\mathrm{P}<0.0001)$. In control group, VAS score showed a non-significant increase in VAS score from $5.93 \pm 2.11(95 \% \mathrm{CI}$
\end{abstract}


4.81 - 7.06) to $6.73 \pm 2.01$ (95\% CI $5.61-7.85)(\mathrm{P}=0.2844)$. Results indicate reduction of pain VAS scores in the PNFS-TMC group $(\mathrm{P}<0.0001)$. Eleven patients $(68.7 \%)$ experienced increased capacity to perform daily physical activities $\mathrm{P}<0.0001$ and $5(31.2 \%)$ showed no change in activity $\mathrm{P}<0.0418 .5$ (33.3\%) of the patients in the control group became worse and $10(66.7 \%)$ experienced no change. Conclusions: PNFS-TMC could offer a simple, safe, cheap and effective method of pain management in chronic PKO patients.

\section{Keywords}

Peripheral Nerve Field Stimulation, Thermal Microcautery, Painful Osteoarthritis, Agni-Karma

\section{Introduction}

Chronic pain conditions are disabling to patients' quality of life including the patients' capacity to carry out day to day activities which require physical activity. Managing chronic pain poses difficulties and challenges, regardless of whether pharmacological or non-pharmacological methods are employed. Pharmacological treatments in pain management, however, can have multiple and varied side effects [1]. Painful knee osteoarthritis (PKO) is linked to severe morbidity [2], thus management of such conditions is important. The general recommended treatment for patients who suffer from osteoarthritis of the knee is firstly to use topical NSAIDs, followed by paracetamol as a form of rescue treatment if the patient still feels pain. Topical NSAID treatments are utilized so widely with a low risk:benefit ratio; however, the risks of their uses are yet to be elucidated [2] [3]. Nevertheless, NSAIDs as peroral medication have a variety of associated side effects including, gastric [4], and renal [5] side effects. Further medication treatment often leads to the use of opiates for chronic pain management, with little to no effect on the neuropathic element of pain [6]. Opioid related problems such as tolerance, resistance and opioid induced hyperalgesia and further risks when combined with anti-depressants or anticonvulsants can be problematic [6] [7].

The non-pharmacological modalities and interventions for PKO can be invasive with risk of complications and costs, thus a search for new modalities for managing chronic pain is still required. Total knee replacement (TKR) is offered to long term sufferers. The procedure is costly, often coincides with pharmacological treatment and can have serious adverse complications. Neuromuscular exercise programmes have been offered as one potential alternative [8] [9] [10], however the likelihood of noncompliance to a recommended physiotherapy to be sustained is common [11].

Agni-karma is a known technique in Ayurveda (an Indian system of Medicine) that employs thermal microcautery to the skin over painful areas for the treatment of severe chronic pain [12]. The microcautery is applied to the point 
of maximum pain through the angled and tapered tip (pin-point) of a metal rod after heating over an open flame until it is red. Quick touch application for about 0.3 - 0.5 seconds over the target skin point produces a second degree burn with an area of about $1 \mathrm{~mm}$ in diameter. A soothing cream is immediately applied, and healing is allowed over a period of two weeks.

Agnikarma, has been evaluated in several studies to treat some chronic pain conditions such as painful knee osteoarthritis [13] [14], sciatica [15] and tennis elbow [16] with a high clinical success rate in managing these chronic pain conditions.

Heat therapy [17] [18] and neuromodulation techniques such as Peripheral Nerve Field Stimulation (PNFS) by electricity [19] [20] [21] are known methods of pain management. Peripheral nerve field stimulation (PNFS) is the stimulation of unnamed small nerves in the vicinity of pain by superficial, subcutaneous lead placement. Explanatory theories for the mechanism of PNFS by thermal microcautery in treating pain include; firstly, resetting the descending inhibitory pathway (DIP) as burn induced inflammation stimulates DIP [22] [23] producing an immediate relief of pain; secondly, deeper burns invariably damage the nerve endings with possible prevention of transmission of any further painful stimuli originating from the original chronic pain source. As the nerves recover, the pain symptoms recur and hence the need for repeated microcauterization to jump the descending inhibitory pathway again. PNFS-TMC is a thermal microcautery that does not produce much burn (with regard to both surface area and depth of burn) so, maybe these proposed mechanisms are not valid to explain the beneficial effects of PNFS-TMC (Agnikarma) [13] [14] [15] [16] [24].

Other explanations for the mechanism of PNFS-TMC in treating chronic pain may include the Gate Theory of Pain [25], the role of the local capsaicin receptor TRVP1 [26], alterations in the signaling within the Dorsal Root Ganglion (DRG), which is now a target for focal neuromodulation [27] or, that chronic pain alters the brain maps of the affected dermatome area on the sensory cortex analogous to mechanisms proposed by Herta Flor [28] [29].

Further mechanisms explain the beneficial effects of Agni-karma may relate to the connections of both peripheral and central mechanisms related to offset analgesia (OA) [30] where the application of a peripheral heat produces an analgesic effect through a temporal filtering of the supplied nociceptive information to the CNS. OA results in decreased activity in SI (primary somatosensory cortex), but is accompanied with higher activation in the inferior parietal lobule, intra-parietal sulcus, anterior insula and dorso-lateral prefrontal cortex [31].

The first and fourth authors of this paper have personal experience of working in India with an Indian based Agni-karma group. The authors were impressed with the immediate and long-term outcomes of using Agni-Karma in chronic pain conditions in India. The clinical studies on PNFS-TMC, however, are not numerous [13] [14] [15] [16], therefore more structured clinical studies are needed to assess and validate PNFS-TMC as a modality in the management of chronic pain. 
The purpose of the current study is to assess the efficacy and the safety of using Peripheral Nerve Field Stimulation by Thermal Microcautery (PNFS-TMC) technique to manage cases with painful knee osteoarthritis.

\section{Methods}

The study was approved by the Research and Ethics Committee at Adelaide and Meath incorporating National Children's Hospital-AMNCH (Tallaght University Hospital). REC reference: 2016-10 Chairman's Action (3) (Appendix 1) and the trial was registered after recruitment of the targeted sample size (ClinicalTrials.gov Identifier: NCT03460717-Registration date: $9^{\text {th }}$ of March 2018). The research was conducted in accordance with the regulations and guidelines of the European Network of Research Ethics Committees.

The study was designed as a non-randomized controlled trial. The technique of PNFS-TMC was introduced for the first time in Ireland and as a result, randomization was not possible. Patients with Painful Knee Osteoarthritis (PKO) who were waiting for TKR were offered PNS-TMC in addition to the standard analgesic care (Appendix 2).

All PKO patients with expected waiting time for TKR $>6$ months were offered PNFS-TMC following full explanation of the technique including its benefits and risks including any possible complications. A website for the Global Agni-karma group (http://globalagnikarma.com) was supplied to the patients as an educational tool to educate patients about the technique. An additional information leaflet was provided (Appendix 3). Information was supplied to the patients through an initial phone call and then through a face to face meeting in the hospital following primary declaration of interest in the idea of PNFS-TMC.

All patients provided written informed consent for participation in the study (Appendix 4). Patients were allocated to one of two groups: 1) Intervention group; included patients who agreed to receive PNFS-TMC in addition to the standard WHO stepladder analgesics. 2) Control group; included patients who declined to have PNFS-TMC and decided to receive only the standard WHO stepladder analgesics.

Inclusion criteria:

- Patients who agree to receive PNFS-TMC to be included in the intervention group.

- Patients who declined to receive PNFS-TMC to be included in the control group.

- History of painful knee osteoarthritis is $>2$ years diagnosed by the Orthopedic service.

- Planned TKR to be $>6$ months after time of recruitment of the patient.

- Intact healthy skin over and around the knee joint.

Exclusion criteria:

- Patients who decline PNFS-TMC to be excluded from the intervention group. 
- History of painful knee osteoarthritis is $<2$ years or the presence of any other causes for painful knee in addition to the osteoarthritis.

- Planned TKR to be $<6$ months after time of recruitment of the patient.

- Inability to apply PNFS-TMC to the skin over and around the knee joint due to infection or inflammation.

A total of 46 patients from the list of TKR patients on an orthopedic waiting list were phoned and offered participation in the study. 16 patients declined PNFS-TMC and were subsequently included in the control group, 30 patients agreed to receive PNFS-TMC and were included in the intervention group. 14 patients out of 30 patients in the intervention group could not complete 4 sessions, these patients were excluded from the analysis. 16 intervention group patients were therefore subject to analysis (Figure 1).

\section{Patients Flow Diagram in PNFS-TMC (Agni-karma) Study}

\section{Enrollment}

A total of 46 patients from TKR waiting Orthopedic list were offered PNFS-TMC

\begin{tabular}{|l|l|}
\hline \multicolumn{2}{|c|}{ Control Group } \\
\begin{tabular}{|l|l|}
16 patients declined PNFS- \\
TMC and were assigned to the \\
control group. $(\mathrm{n}=16)$
\end{tabular} \\
\hline
\end{tabular}

Excluded $(n=2)$

- Admitted from the waiting list to TKR before the start of PNFS-TMC sessions $(n=2)$

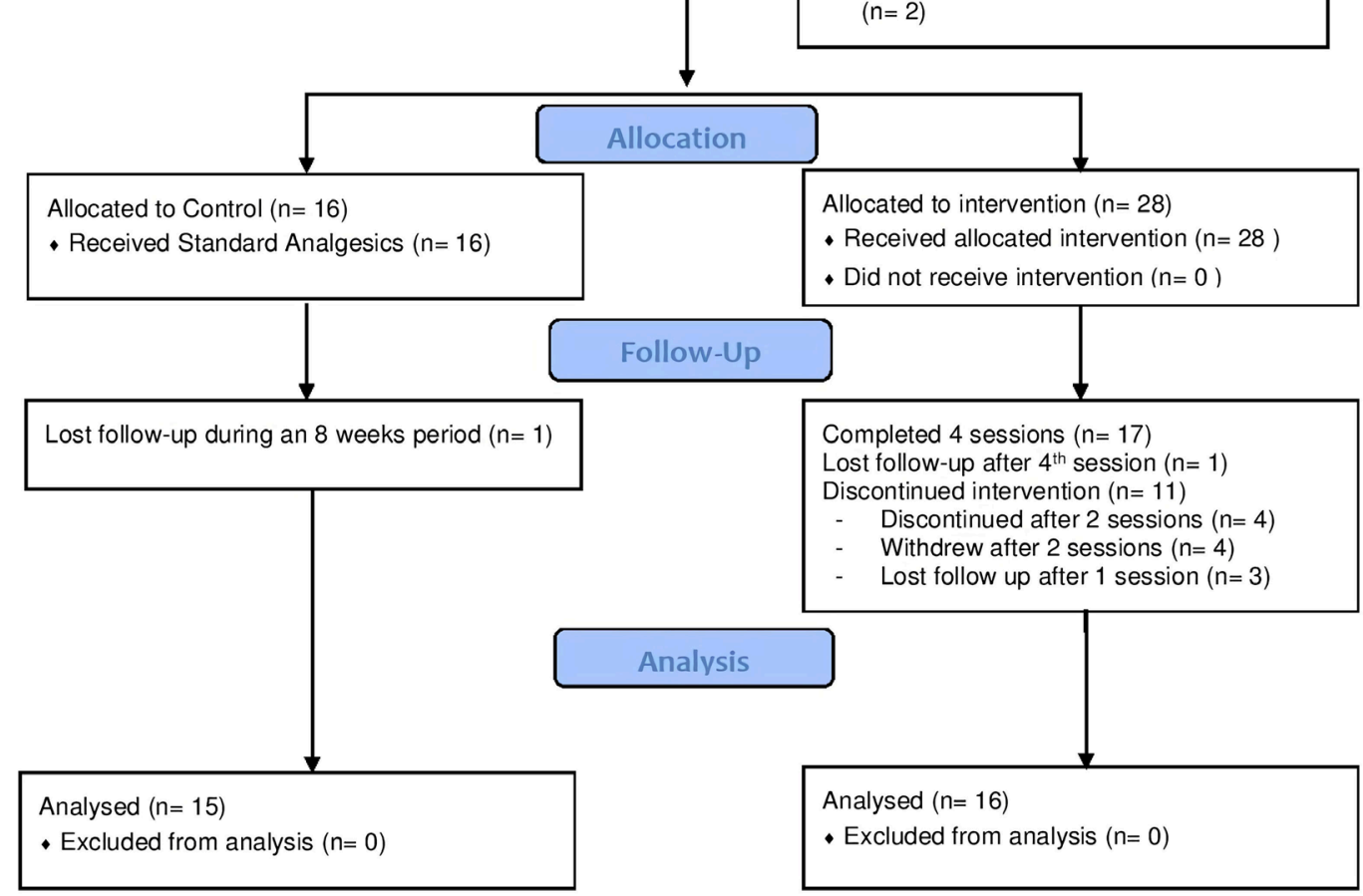

Figure 1. Patients flow diagram. 


\subsection{Intervention: PNFS-TMC}

The intervention group patients were scheduled to have 4 sessions, 2 weeks apart, over a period of 8 weeks. During each session, the most painful points over the knee joint on palpation were determined, marked and recorded and treated as "points of tenderness". Skin sterilization was not utilized before the procedure as temperature used $\left(371^{\circ} \mathrm{C}-649^{\circ} \mathrm{C}\right)$ was sufficient to destroy even prions which will denature at $135^{\circ} \mathrm{C}$ [32]. The pin pointed tip of the metal rod (Shalaka), which is composed of Brass (a metal alloy of copper and zinc) was heated over an open naked flame for 5 minutes, until the tip became red in color (Figure 2). The temperature of the heated rod lies within in the range of $371^{\circ} \mathrm{C}$ $649^{\circ} \mathrm{C}$. Each marked skin point was touched with the pin point tip of the hot metal rod for 0.3 to 0.5 second. The aim was to produce a micro second-degree burn, with an area of about $1 \mathrm{~mm}$ in diameter and a depth of less than $1 \mathrm{~mm}$. Immediately following removal of the hot metal rod away from the skin, the burned point was covered by a soothing herbal cream to alleviate any pain caused by the treatment. The cream was herbal based [Burncool cream-license number (India) GA/1555-Pistacia lentiscus $0.2 \%$, Shorea robusta 9\%, Sesamum indicum 15\%, coconut oil 15\%, bees' wax 2\% and water QS (Quantum Satis)]. Patients reported that the cream immediately cools the burned area and therefore makes the treatment acceptable for the patient (Video 1).

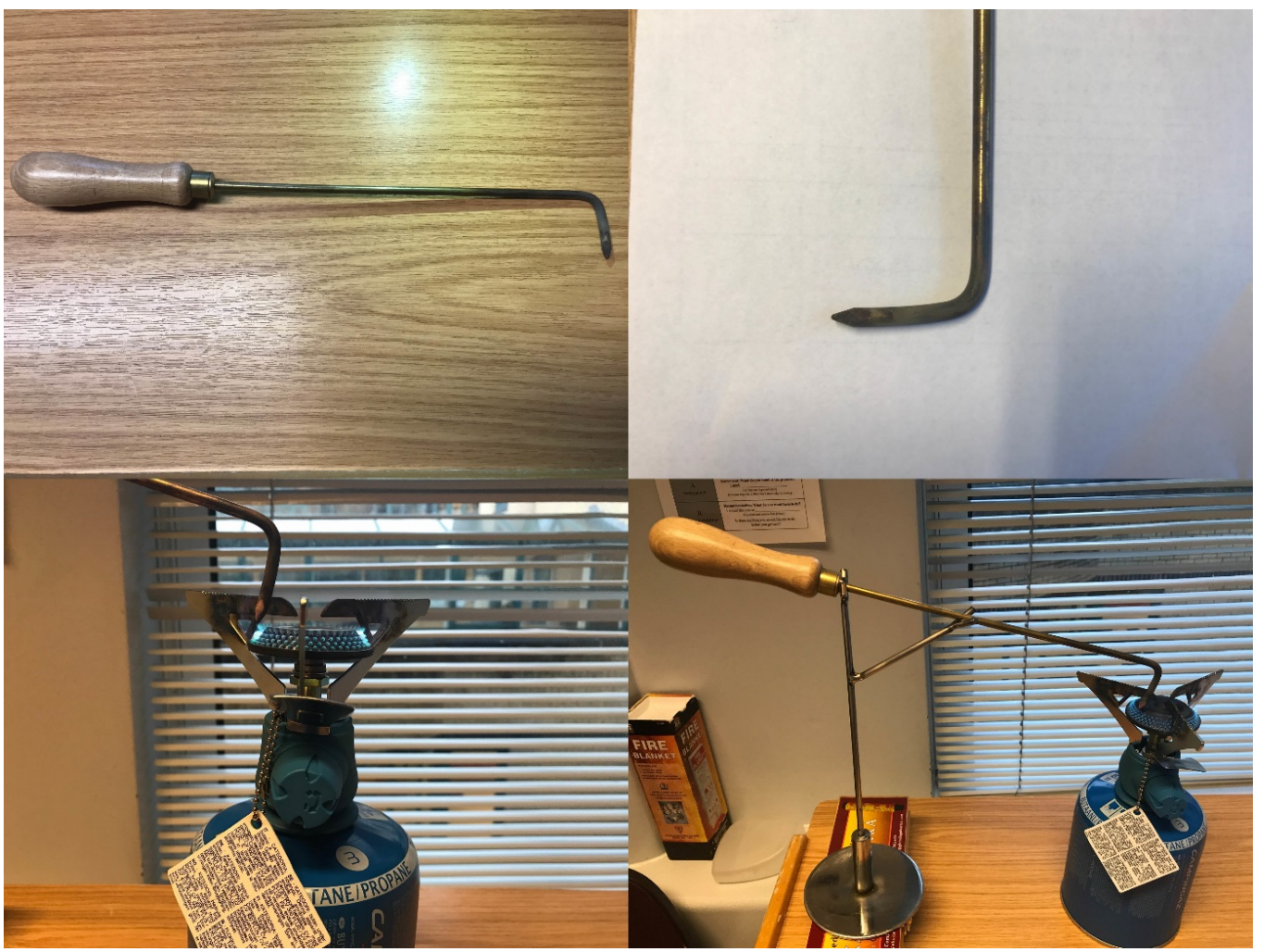

Figure 2. Upper left; the metal rod or Shalaka made of Brass, alloy of copper and zinc. Upper right, the pointed tip of the metal rod used to apply PNFS-TMC. Lower right, the metal rod is suspended with its tip in open flame. Lower left, the tip heated until it is red. 


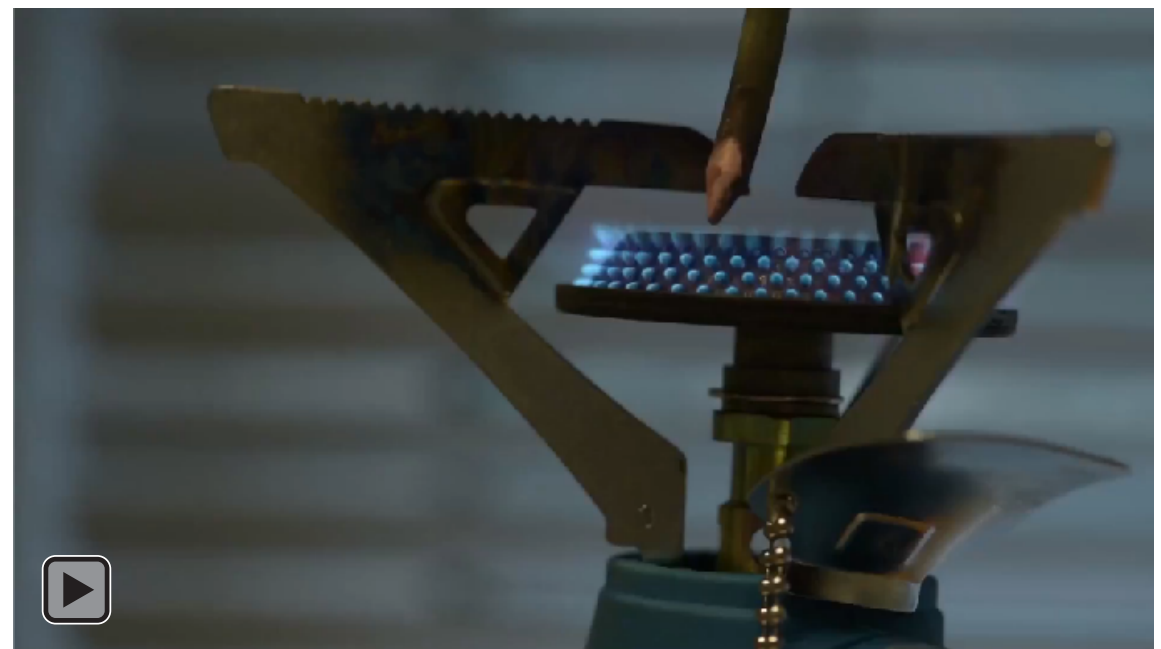

Video 1. Each marked skin point was touched with the pin point tip of the hot metal rod for 0.3 to 0.5 second. The aim was to produce a micro second-degree burn, with an area of about $1 \mathrm{~mm}$ in diameter and a depth of less than $1 \mathrm{~mm}$. Immediately following removal of the hot metal rod away from the skin, the burned point was covered by a soothing herbal cream to alleviate any pain caused by the treatment. The cream was herbal based [Burncool cream-license number (India) GA/1555-Pistacia lentiscus $0.2 \%$, Shorea robusta 9\%, Sesamum indicum 15\%, coconut oil 15\%, bees' wax 2\% and water QS (Quantum Satis)]. Patients reported that the cream immediately cools the burned area and therefore makes the treatment acceptable for the patient.

The procedure was repeated for other marked painful points. The central line for the future standard surgical incision for TKR was totally avoided. These painful points could vary between sessions both in nature and location. They are defined as points of maximum tenderness within an area of allodynia. The boundaries of the area of allodynia were defined first by palpation and then within that demarcated area the precise pain points were agreed upon by the patient.

In cases where the patient had two affected knees the procedure was applied to the worst affected knee before the second to mimic the order of treatment that would be given during knee replacement.

The thermal micro-cautery was applied by author one in all cases (previous training in the procedure had taken place at the Global Agni-karma Centre).The same instrument was used for all patients. All fire safety precautions were taken.

All patients were advised to continue their normal therapy and to use this intervention as an adjunctive therapy. In a similar fashion, control patients were advised to continue their normal therapy.

\subsection{Data Collection}

Data was collected from patients in both groups. The primary outcome was change in VAS pain score which was recorded twice. Initially a baseline VAS was recorded at the time of recruitment (before any intervention), and then again after 8 weeks (i.e. after 4 sessions in the intervention group and 2 weeks after the last session). 
VAS pain score was obtained verbally by a phone call in the control group, after explaining the score to the patients. Secondary outcomes were recorded subjectively. Changes in daily activity (improved, worsened or no change), changes in sleep quality (improved, worsened, no change) and changes in analgesics usage (increased, decreased, no change). Data was collected both over the phone and during the sessions.

\subsection{Sample Size Calculation}

We hypothesized a 50\% reduction in VAS pain scores for patients with PKO who received PNFS-TMC (Agni-karma) as a primary outcome [13] [14]. Allowance was made for a type one alpha error of 0.05 , power 0.9 with a smallest effect size of $40 \%$, standard deviation 10. Based on this data, a power of $32 \mathrm{pa}$ tients was established with 16 patients in each group. Sample size calculation was estimated by using $G^{\star}$ Power software version 3.1.9.2 (Institute of Experimental Psychology, Heinrich Heine University, Dusseldorf, Germany).

\subsection{Statistical Analysis}

Data of patients' characteristics were compared by independent $t$-test. Other categorical variables were evaluated by chi-square test or Fisher's exact test when appropriate. All values expressed as mean \pm standard deviation, median (interquartile range), or number of participants (percent) as appropriate. A P $<0.05$ was considered statistically significant. Statistical analysis was performed using MedCalc Statistical Software version 17.7.2 (MedCalc Software bvba, Ostend, Belgium; http://www.medcalc.org; 2017)

\section{Results}

The trial was carried out in the period from December 2016 to August 2017. A total of 46 patients with PKO and expected waiting time for TKR $>6$ months were offered to receive PNFS-TMC in addition to routine care. 16 patients declined PNFS-TMC and were assigned to the control group with one patient lost to follow up during the 8 weeks follow up. 30 patients agreed to have PNFS-TMC. 17 patients completed all 4 sessions. One patient was lost to follow up after the fourth session. Data from 16 patients in the intervention group and 15 patients in the control group were analysed (Figure 1).

16 (14 female) patients completed 4 sessions of PNFS-TMC-Mean age 64.76 (SD 9.98). 15 (13 female) patients were followed in the waiting list control-Mean age 71.56 (SD 9.82) with no significant difference between the groups in age nor gender distribution (Table 1).

The baseline VAS score was significantly higher in the PNFS-TMC group than in the Control group [ $9 \pm 1.23$ (95\% CI 8.38 to 9.61 ) versus $5.93 \pm 2.11$ (CI 95\% 4.81 to 7.06 ) respectively with $\mathrm{P}<0.0001$ ] (Table 1 ).

The VAS score after 8 weeks (i.e. 4 sessions), was significantly lower in the PNFS-TMC group than in the Control group [4.64 \pm 2.08 (95\% CI 3.57 to 5.72 ) 
Table 1. VAS score in intervention and control groups.

\begin{tabular}{|c|c|c|c|c|}
\hline & & Intervention group & Control group & $P$ value \\
\hline \multicolumn{2}{|c|}{ Number of patients (M/F) } & $17(3 / 14)$ & $16(3 / 13)$ & 0.9357 \\
\hline \multicolumn{2}{|c|}{ Age $\pm S D$ (years) } & 64.76 (SD 9.98) & 71.56 (SD 9.82) & 0.0577 \\
\hline \multirow{2}{*}{ Initial VAS } & Mean \pm SD & $\begin{array}{c}9 \pm 1.23 \\
(95 \% \text { CI } 8.38 \text { to } 9.61)\end{array}$ & $\begin{array}{c}5.93 \pm 2.11 \\
\text { (CI } 95 \% 4.81 \text { to } 7.06)\end{array}$ & \multirow{2}{*}{$<0.0001^{*}$} \\
\hline & $\begin{array}{l}\text { Range } \\
\text { (Median) }\end{array}$ & $\begin{array}{l}6-10 \\
(9.5)\end{array}$ & $\begin{array}{c}1-9 \\
(7)\end{array}$ & \\
\hline \multirow{2}{*}{$\begin{array}{l}\text { VAS after } 8 \text { weeks } \\
\text { (i.e. after } 4 \text { sessions in the } \\
\text { Intervention group) }\end{array}$} & Mean \pm SD & $\begin{array}{c}4.64 \pm 2.08 \\
(95 \% \text { CI } 3.57 \text { to } 5.72)\end{array}$ & $\begin{array}{c}6.73 \pm 2.01 \\
(95 \% \text { CI } 5.61 \text { to } 7.85) .\end{array}$ & \multirow[t]{2}{*}{$0.0058^{*}$} \\
\hline & $\begin{array}{c}\text { Range } \\
\text { (Median) }\end{array}$ & $\begin{array}{c}1-8 \\
(5)\end{array}$ & $\begin{array}{l}3-9 \\
(7)\end{array}$ & \\
\hline \multicolumn{2}{|c|}{ Intra-Group comparison (VAS) } & $\mathrm{P}<0.0001^{*}$ & $\mathrm{P}=0.2844$ & \\
\hline
\end{tabular}

VAS: Visual Analogue Score. P value $<0.05$ is considered statistically significant.

versus $6.73 \pm 2.01$ (95\% CI 5.61 to 7.85 ) respectively with $\mathrm{P}=0.0058$ ] (Table 1 ).

In the PNFS-TMC group, VAS score decreased significantly from $9 \pm 1.23$ (95\% CI 8.38 to 9.61$)$ at baseline to $4.64 \pm 2.08$ (95\% CI 3.57 to 5.72 ) after 4 sessions $(\mathrm{P}<0.0001)$. While in the control group, VAS score showed a non-significant increase in VAS score from $5.93 \pm 2.11$ (CI 95\% 4.81 to 7.06$)$ to $6.73 \pm 2.01$ (95\% CI 5.61 to 7.85$)$ after 8 weeks $(\mathrm{P}=0.2844)$ (Table 1$)$.

The majority of Patients in the PNFS-TMC group experienced improved daily activity, compared to none of the patients in the control group (11 patients $(68.7 \%)$ versus $0 \%$ respectively, $\mathrm{P}<0.0001)$. None of the PNFS-TMC patients reported worsening of daily activity versus 5 patients $(33.3 \%)$ in the control group, $\mathrm{P}<0.0001$. The majority of patients [10 patients $(66.7 \%)]$ in the control group had no change in daily activity versus 5 patients $(31.2 \%)$ in the PNS-TMC group, $\mathrm{P}=0.0418$ (Table 2).

The majority of patients in both groups showed no change in sleep quality [62.5\% in PNFS-TMC group versus $80 \%$ in control group, $\mathrm{P}=0.3018$ ], 6 patients (37.5\%) in PNFS-TMC group had improved sleep versus none in the control group $(\mathrm{P}<0.0001) .3$ patients $(20 \%)$ had worsening of sleep quality versus none in the PNFS-TMC group $(\mathrm{P}<0.0001)$.

About the analgesic requirements, most patients in both groups experienced no change in analgesic needs (15 patients (93.7\%) in PNFS-TMC group versus 13 patients $(86.7 \%)$ in the control group, $\mathrm{P}=0.5171$ ) (Table 2 ).

In the PNFS-TMC group: 6 patients (40\%) were interested in having more sessions, while 9 patients $(60 \%)$ were not interested in having more sessions. However out of these 9 patients, 4 patients (26.66\%) were not interested because satisfaction of the level of pain relief. 2 patients (12.5\%), out of the 16 patients in the Intervention group cancelled their TKR as pain level decreased to a satisfactory level (Table 3 ).

Regression analysis showed a significant correlation between best pain score after 4 sessions and activity after 4 sessions in PNFS-TMC group ( $2=0.006, \mathrm{P}$ $=0.0285)$. 
Table 2. Secondary outcomes in intervention and control groups.

\begin{tabular}{|c|c|c|c|}
\hline & $\begin{array}{l}\text { Intervention group } \\
\quad(16 \text { patients })\end{array}$ & $\begin{array}{l}\text { Control group } \\
\text { (15 patients) }\end{array}$ & $P$ value \\
\hline \multirow{3}{*}{$\begin{array}{l}\text { Change in daily activity } \\
\text { after } 8 \text { weeks }\end{array}$} & Improved: 11 (68.7\%) & Improved: $0 \%$ & $<0.0001^{*}$ \\
\hline & Worsened: $0 \%$ & Worsened: 5 (33.3\%) & $<0.0001^{\star}$ \\
\hline & No change: 5 (31.2\%) & No change: 10 (66.7\%) & $0.0418^{*}$ \\
\hline \multirow{3}{*}{$\begin{array}{c}\text { Change in sleep after } 8 \\
\text { weeks }\end{array}$} & Improved: 6 (37.5\%) & Improved: 0 & $<0.0001^{\star}$ \\
\hline & Worsened: 0 & Worsened: 3 (20\%) & $<0.0001^{\star}$ \\
\hline & No change: 10 (62.5\%) & No change: $12(80 \%)$ & 0.3018 \\
\hline Change in analgesic & Decreased: 1 (6.2\%) & Decreased: $1(6.7 \%)$ & 1.0000 \\
\hline requirement after 8 & Increased: 0 & Increased: $1(6.7 \%)$ & 0.3005 \\
\hline weeks & No change: 15 (93.7\%) & No change: 13 (86.7\%) & 0.5171 \\
\hline
\end{tabular}

*: P value $<0.05$ is considered statistically significant.

Table 3. Outcomes in the intervention group.

\begin{tabular}{cc}
\hline Outcome & \\
\hline Interest in having more sessions & 6 patients $(40 \%)$ \\
Satisfied with level of pain relief & 9 patients $(60 \%)$ \\
Cancelled TKR due to satisfaction with pain relief & 2 patients $(13.3 \%)$ \\
\hline
\end{tabular}

\section{Discussion}

The current trial shows that Peripheral Nerve Field Stimulation by Thermal Microcautery (PNFS-TMC), otherwise known as Agni-Karma in Ayurvedic medicine, is potentially effective when used as an adjunct to standard WHO stepladder analgesics in managing chronic pain due to knee osteoarthritis. PNFS-TMC significantly reduced VAS by about $50 \%(\mathrm{P}<0.0001)$ after 4 sessions as compared to control patients who experienced mild non-significant increase in VAS $(\mathrm{P}=0.2844)$ after the same period. Interestingly, although PNFS-TMC group had a significantly higher baseline VAS than the control group [ $9 \pm 1.23$ (95\% CI 8.38 to 9.61 ) versus $5.93 \pm 2.11$ (CI 95\% 4.81 to 7.06 ), $\mathrm{P}<0.0001$ ], PNFS-TMC patients achieved a significantly lower VAS than the control group after 8 weeks [4.64 \pm 2.08 (95\% CI 3.57 to 5.72 ) versus $6.73 \pm 2.01$ (95\% CI 5.61 to 7.85 ) respectively with $\mathrm{P}=0.0058]$.

PNFS-TMC resulted in improved daily activity in a majority of patients (68.7\%) which did not happen with any patient in the control group $(\mathrm{P}<$ 0.0001). PNFS-TMC was associated with improved sleep in 6 patients $(37.5 \%)$ which did not happen with any patient in the control group $(\mathrm{P}<0.0001)$. None of the patients who received PNFS-TMC experienced deterioration in sleep nor daily activity. Both groups declared comparable analgesic consumption.

The current study presents evidence of the clinical effect of PNFS-TMC (Agnikarma) for the relief of pain in patients with knee osteoarthritis who are on a waiting list for TKR. We document a 50\% reduction in pain score after 4 sessions of therapy delivered over an 8-week period. Of note, the interventional group had a higher initial VAS score, this might be due to more osteoarthritis 
and more pain or it might be due to poor response of these patients to medications. The higher baseline VAS of the intervention group patients may be their reason to accept participation in the study. PNFS-TMC significantly reduced this high VAS score when compared to the control patients which suggests the efficacy of PNFS-TMC. The analgesia induced by PNFS-TMC was associated with improved activity and sleep. Two patients cancelled their TKR due to satisfaction with the level of pain relief and improved activity. This was an unexpected outcome but hints at the potential pain relief capacity of the technique for some.

It is a standard teaching in Pain Medicine that improvements in pain scores which are subjective need to be linked with improvements in function. An example of this would be, the support for a prescription of opioids in chronic pain would follow documentation of a $50 \%$ improvement in pain associated with better function in the activities of daily living in an initial trial of therapy. This philosophy permeates into acute post-operative medicine also, where fast track rehabilitation strategies post-operatively attempt to combine the improved pain scores and thus improved the pain management of recovery. Improved function, sleep and stable medication in the interventional group were also recorded. These findings support the primary outcome's finding of a pain score reduction after 4 sessions by framing it with meaningful improvements in quality of life as measured by improvement in daily activities and some with better sleep quality. These results are in stark contrast to the status quo of knee pain sufferers, including when compared to the deterioration expressed by the control group. It is interesting to note that the comparative waiting list control group deteriorated during their period of waiting. There was no meaningful difference in the use of medication, however, patients were not asked to alter their medication as such an instruction might be unethical without having enough valid evidence for analgesia through Agnikarma. A future design with PRN medication use option might explore this issue further.

The objective of studying Agni-karma is both to document benefits worthy of further investigation and to stimulate a conversation about possible mechanisms of action so that a further hypothesis can be generated. Indeed, the possibility of a better understanding of mechanism might offer a pathway to new treatments.

The pre-requisites for Thermal Microcautery to work seem to be, 1) Presence of maximal pain points or focal points of tenderness. 2) Acute second degree burn to the area. 3) Treatment probably repeated at 1 - 2-week intervals, most effective when completed over several sessions. 4) An early treatment effect which could start within hours of the initial burn.

Heat treatment has evidently managed chronic pain in other instances [13] [14] [15] [16] [24]. A possible explanation of the mechanism by which PNFS-TMC produces such analgesic effects includes peripheral nerve field stimulation by heat [30].

Pain itself has two features, temporal and spatial [33]. The analgesic effect of CPM (Conditioned Pain Modulation) has been linked to filtering of the spatial 
feature while the OA (Offset Analgesia) has been linked to filtering through temporal features [30] [31] [34]. One explanation proposed has been that heat effects CPM [35]. This mechanism may not be applicable to PNFS-TMC as CPM does not happen if the time of stimulation is shorter than 20 seconds [36] while the time of PNFS-TMC is $0.3-0.5 \mathrm{~s}$. To further add to this; the nature of the burn produced by PNFS-TMC (a micro second degree burn) favors the concept of offset analgesia (OA) [30] [31] [34] as a possible explanation for the effectiveness of PNFS-TMC in managing pain conditions.

OA depends on applying two different temperatures peripherally which is applicable to PNFS-TMC as there are two different temperatures, an initial high temperature $\left(371^{\circ} \mathrm{C}-649^{\circ} \mathrm{C}\right)$ followed by a lower temperature induced by application of cold soothing cream (room temperature $20^{\circ} \mathrm{C}$ ). Although, $\mathrm{OA}$ is mainly connected to filtering the temporal component of pain [23], recent studies [30] [33] [34] suggested that OA has a spatial component in addition to the temporal component. OA can be applied on the findings in our study, where the spatial component can be due to superficial stimulation (burn by PNFS-TMC) coupled with deep stimulation by signals from deeper inflamed tissues. The temporal component arises due to the time difference between the two temperatures applied during PNFS-TMC $\left(371^{\circ} \mathrm{C}-649^{\circ} \mathrm{C}\right.$ followed by $\left.20^{\circ} \mathrm{C}\right)$.

The finding of a greater improvement from the high VAS intervention group was interesting. It is possible that people with a higher pain perception may have a higher sensitivity to peripheral nerve field stimulation, regardless of the mechanism through which pain alleviation operates.

The VAS score showed a non-significant increase in the control group. A possible explanation is the progressive deterioration in knee osteoarthritis with the patients' daily activity or natural variability in a chronic condition for which analgesia is not consistently efficacious.

OA has been proved to be non-dependent on either ketamine [36] [37] nor opioids [37]. A functional MRI study [31] showed that OA produces a significant reduction in pain intensity associated with decreased activity in SI (primary somatosensory cortex), but is accompanied with higher activation in the inferior parietal lobule, intraparietal sulcus, anterior insula and dorso-lateral prefrontal cortex [38] [39].

Our preferred modern descriptive term is "Peripheral Nerve Field Stimulation by Thermal Microcautery". This captures the necessity to find peripheral maximal pain points within the painful area which do not relate to an anatomical area and seem to represent a field of painful activity. Such an area has a neural and perhaps ultimately, a brain link. The repetitive nature of the intervention categorizes it as stimulation-karma in the original title translates as action. Cautery is descriptive for the intervention and loyal to the traditional name of the procedure (Agni translates as fire). Together the total descriptive term fits with the modern concept of peripheral nerve field stimulation which attempts to modulate the peripheral nerve field by electric means as opposed to our traditional stimulation by thermal microcautery. 
We took the view that 4 sessions were a reasonable number, however, patient populations that do not normally attend a Pain Clinic showed a trend in lack of completion. A significant number of patients failed to stay in the study to complete 4 sessions of therapy. We looked at their reasons for withdrawal as documented in the results section which included 2 who received no improvement after two sessions. Other patient withdrawals occurred despite documented improvements. Some patients were lost to follow up after one session. Our primary objective was to calculate VAS after 4 completed sessions. We therefore only considered those results to test the hypothesis that 4 sessions of Agni-karma would demonstrate a positive trend in pain relief.

Our results agree with the few clinical studies published on the use of Agni-karma in different conditions of pain as PKO [14], sciatica [15] and tennis elbow [16]. The Agni-karma for the PKO studies [14] was delivered in a traditional manner for knee pain using two different temperatures. One technique applied the heat to the brass instrument for 5 minutes pre-application. The other time period of heating the instrument was longer, heating for 15 minutes pre-application. Interestingly, they revealed a greater effect of Agnikarma with higher temperature (longer heating). Our set up is was akin to the lower temperature, we waited approximately 5 minutes pre-application. The precise temperature of the probe was not the focus of this study however the tip of metal rod was red in colour before application to the skin. They also used a 4-session model and studied two groups of 28 . In their overall assessment they recorded that over $50 \%$ of their patients had improved pain scores.

None of our patients reported any complications related to the thermal microcautery applied to the skin with almost complete healing of the induced second degree burn. This may be due to the brief contact with the skin (0.3 - 0.5 second) and the very small area of burn (about $1 \mathrm{~mm}$ ).

There is certainly an art in the degree of pressure to apply which is shown in the video (Video 1) which demonstrates the procedure. We did not instruct the patients to reduce the analgesia doses that they were regularly taking for PKO because we did not have certainty about the effect of PNFS-TMC. Future studies may include such instructions and measurement of the analgesic requirements.

\section{Conclusion}

PNFS-TMC may offer a simple, safe, cheap and effective method to manage chronic painful knee osteoarthritis. The effects of PNFS-TMC were reflected by significant improvements in pain score, activity and sleep with none of the patients experiencing any complications. Further studies including larger sample size with different pain conditions are required. Future studies may include functional MRI to further investigate the possible mechanisms of PNFS-TMC.

\section{Limitations and Future Studies}

One of the limitations of the current study is that it is a non-randomized trial which could undermine the validity and generalizability of our results. Due to 
the novel nature of the intervention, and it being used in clinical practice for the first time in Europe, we had to offer PNFS-TMC to our patients and allocate patients who agreed to the intervention group and patients who refused to the control arm. This is partially compensated by having a control arm to which the intervention has been compared.

Another limitation was the use of a probe heated for a period of 5 minutes only for PNFS-TMC. Additionally, our trial did not analyze precisely the analgesia consumption by the patients.

Another limitation of our trial is that it is a single center trial and recruited a relatively small sample size for a limited number of sessions. Our sample size is comparable to Jethava, N.G. et al. [10] who examined Agni-karma on 28 patients with $\mathrm{PKO}$, however a more comprehensive study would be required to derive reproducible conclusions.

Data derived from this trial will be used to plan for another trial which will assess the use of PNFS-TMC in different localized pain conditions such as back pain, shoulder pain and knee pain.

\section{Acknowledgements}

The authors acknowledge; Vaidya Asvin Barot (UK) for research rediscovery and development of concept. Also, Global Agnikarma Centre, Ahmedabad, Gujarat, India-Vaidyas Hitesh Chauhan, Hardik Darji, Krishna Patel, Hetal Chauhan, staff and patients for clinical access, training and the educational website. Finally, Consultant Orthopedic Surgeons at Tallaght University Hospital, Dublin, Ireland. Mr. John Quinlan and Mr. Tom McCarthy_for allowing the authors to access their waiting lists of patients for TKR.

\section{Data Availability}

Data will be available upon reasonable request.

\section{Institutional Attribution of the Work}

Department of Pain Medicine, Tallaght University Hospital, Trinity College, University of Dublin, Ireland.

\section{Authors Contributions}

\section{1) Camillus K. Power:}

Study design, clinical application of the technique, supervision of the research, writing the primary manuscript, revision and approval of the final manuscript.

2) Deborah Galvin:

Application for Ethical Committee approval, data collection, revision and approval of the final manuscript.

\section{3) Tagarisa Foto:}

Patients recruitment and follow-up, data collection, revision and approval of the final manuscript. 


\section{4) Ahmed Abdelaal Ahmed Mahmoud:}

Data analysis, participated in study design, revision and approval of the final manuscript.

5) Nikolaos G. Kostopoulos:

Revision and approval of the final manuscript.

\section{Research and Ethics Committee Approval}

The study was approved by REC at Tallaght University Hospital (Adelaide and Meath incorporating National Children's Hospital) on the $11^{\text {th }}$ of October 2016. REC Reference: 2016-10 Chairman's Act (3).

\section{Trial Registration}

ClinicalTrials.gov Identifier: NCT03460717; Date of clinical trial registration: $9^{\text {th }}$ of March 2018.

\section{Conflicts of Interest}

The authors declare no conflict of interest.

\section{References}

[1] Mao, J.R. (2017) Challenges of Managing Chronic Pain. British Medical Journal, 356, j741. https://doi.org/10.1136/bmj.j741

[2] Rannou, F., Pelletier, J.P. and Martel-Pelletier, J. (2016) Efficacy and Safety of Topical NSAIDs in the Management of Osteoarthritis: Evidence from Real-Life Setting Trials and Surveys. Seminars in Arthritis and Rheumatism, 45, S18-S21. https://doi.org/10.1016/j.semarthrit.2015.11.007

[3] Bjordal, J.M., Ljunggren, A.E., Klovning, A. and Slordal, L. (2004) Non-Steroidal Anti-Inflammatory Drugs, Including Cyclo-Oxygenase-2 Inhibitors, in Osteoarthritic Knee Pain: Meta-Analysis of Randomized Placebo Controlled Trials. British Medical Journal, 329, 1317. https://doi.org/10.1136/bmj.38273.626655.63

[4] García-Rayado, G., Navarro, M. and Lanas, A. (2018) NSAID Induced Gastrointestinal Damage and Designing GI-Sparing NSAIDs. Expert Review of Clinical Pharmacology, 11, 1031-1043. https://doi.org/10.1080/17512433.2018.1516143

[5] Sriperumbuduri, S. and Hiremath, S. (2019) The Case for Cautious Consumption: NSAIDs in Chronic Kidney Disease. Current Opinion in Nephrology and Hypertension, 28, 163-170. https://doi.org/10.1097/MNH.0000000000000473

[6] Vellucci, R., Terenzi, R., Kanis, J.A., Kress, H.G., Mediati, R.D., Reginster, J.Y., Rizzoli, R. and Brandi, M.L. (2018) Understanding Osteoporotic Pain and Its Pharmacological Treatment. Osteoporosis International, 29, 1477-1491.

https://doi.org/10.1007/s00198-018-4476-y

[7] Manchikanti, L., Kaye, A.M., Knezevic, N.M., et al. (2017) Responsible, Safe and Effective Prescription of Opioids for Chronic Non-Cancer Pain: An American Society of Interventional Pain Physicians (ASIPP) Guidelines. Pain Physician, 20, S3-S92.

[8] Hernandez, D., Dimaro, M., Navarro, E., Dorado, J., Accoce, M., Salzberg, S. and Policastro, P. (2019) Efficacy of Core Exercises in Patients with Osteoarthritis of the Knee: A Randomized Controlled Clinical Trial. Journal of Bodywork and Movement Therapies. https://doi.org/10.1016/j.jbmt.2019.06.002 
[9] Skou, S.T., Roose, E.M., Laursen, M.B., et al. (2015) A Randomized Control Trial of Total Knee Replacement. The New England Journal of Medicine, 373, 1597-1606.

[10] Ferket, B.S., Feldman, Z., Zhou, J., Oei, H., Bierma-Zeinstra, S. and Mazumdar, M. (2017) Impact of Total Knee Replacement Practice: Cost Effectiveness Analysis of data from the Osteoarthritis Initiative. British Medical Journal, 356, j1131. https://doi.org/10.1136/bmj.j1131

[11] Campbell, R., Evans, M., Tucker, M., Quilty, B., Dieppe, P. and Donovan, J.L. (2001) Why Don't Patients Do Their Exercises? Understanding Non-Compliance with Physiotherapy in Patients with Osteoarthritis of the Knee. Journal of Epidemiology \& Community Health, 55, 132-138. https://doi.org/10.1136/jech.55.2.132

[12] Acharya, J.T. (2009) Varanasi: Chaukhamba Surbharti Prakashan. 18, 51, 52, 420.

[13] Jethava, N.G., Dudhamal, T.S. and Gupta, S.K. (2015) Role of Agnikarma in Sandhigata Vata (Osteoarthritis of Knee Joint). Ayu, 36, 23-28. https://doi.org/10.4103/0974-8520.169017

[14] Sharma, A.V., Dudhamal, T.S., Gupta, S.K. and Mahanta, V. (2016) Clinical Study of Ahnikarma and Panchatikta Guggulu in the Management of Sandhivata (Osteoarthritis of the Knee Joint). Ayu, 37, 38-44.

https://doi.org/10.4103/ayu.AYU $103 \quad 14$

[15] Vaneet Kumar, J., Dudhamal, T.S., Gupta, S.K. and Mahanta, V. (2014) A Comparative Clinical Study of Siravedha and Agnikarma in Management of Gridhrasi (Sciatica). Ayu, 35, 270-276. https://doi.org/10.4103/0974-8520.153743

[16] Mahanta, V., Dudhamal, T.S. and Gupta, S.K. (2013) Management of Tennis Elbow by Agnikarma. Journal of Ayurveda and Integrative Medicine, 4, 45-47. https://doi.org/10.4103/0975-9476.109552

[17] Mc Lean, D.A. (1989) The Use of Cold and Superficial Heat in the Treatment of Soft Tissue Injuries. British Journal of Sports Medicine, 23, 53-54.

[18] Abramson, D.I., Chu, L.S., Tuck, S., Lee, S.W., Richardson, G. and Levin, M. (1966) Effect of Tissue Temperatures and Blood Flow on Motor Nerve Conduction Velocity. The Journal of the American Medical Association, 198, 1082-1088.

[19] Nashold, J.B., Goldner, J.L., Mullen, J.B. and Bright, D.S. (1982) Long-Term Pain Control by Direct Peripheral-Nerve Stimulation. The Journal of Bone and Joint Surgery, 64, 1-10. https://doi.org/10.2106/00004623-198264010-00001

[20] Lord, S.M., Barnsley, L., Wallis, B.J. and McDonald, B.N. (1996) Percutaneous Radio-Frequency Neurotomy for Chronic Cervical Zygapophyseal-Joint Pain. The New England Journal of Medicine, 335, 1721-1726. https://doi.org/10.1056/NEJM199612053352302

[21] Henderson, J.M. (2008) Peripheral Nerve Stimulation for Chronic Pain. Current Pain and Headache Reports, 12, 28-31. https://doi.org/10.1007/s11916-008-0006-5

[22] Vanegas, H. and Schaible, H.G. (2004) Descending Control of Persistent Pain: Inhibitory or Facilitatory? Brain Research Reviews, 46, 295-309. https://doi.org/10.1016/j.brainresrev.2004.07.004

[23] Yelle, M.D., Rogers, J.M. and Coghill, R.C. (2008) Offset Analgesia: A Temporal Contrast Mechanism for Nociceptive Information. Pain, 134, 174-186. https://doi.org/10.1016/j.pain.2007.04.014

[24] Power, C.K., Kostopoulos, N. and Chauhan, H. (2016) Abstract PR327: Agnikarma (Thermal Cauterization)-An International Collaborative Project for a Novel Interventional Pain Management Therapy. Anesthesia \& Analgesia, 123, 422. https://doi.org/10.1213/01.ane.0000492723.81475.70 
[25] Kumar, K. and Rizvi, S. (2014) Historical and Present State of Neuromodulation in Chronic Pain. Current Pain and Headache Reports, 18, 387. https://doi.org/10.1007/s11916-013-0387-y

[26] Szallasi, A. and Sheta, M. (2012) Targeting TRPV1 for Pain Relief: Limits, Losers and Laurels. Expert Opinion on Investigational Drugs, 21, 1351-1362. https://doi.org/10.1517/13543784.2012.704021

[27] Pope, J.E., Dear, T.R. and Kramer, J. (2013) A Systematic Review: Current and Future Directions of Dorsal Root Ganglion Therapeutics to Treat Chronic Pain. Pain Medicine, 14, 1477-1496. https://doi.org/10.1111/pme.12171

[28] Kuner, R. and Flor, H. (2016) Structural Plasticity and Reorganization in Chronic pain. Nature Reviews Neuroscience, 18, 20-30. https://doi.org/10.1038/nrn.2016.162

[29] Flor, H. (2012) New Developments in the Understanding and Management of Persistent Pain. Current Opinion in Psychiatry, 25, 109-113. https://doi.org/10.1097/YCO.0b013e3283503510

[30] Ligato, D., Petersen, K.K., Mørch, C.D. and Arendt-Nielsen, L. (2018) Offset Analgesia: The Role of Peripheral and Central Mechanisms. European Journal of Pain, 22, 142-149. https://doi.org/10.1002/ejp.1110

[31] Nahman-Averbuch, H., Martucci, K.T., Granovsky, Y., Weissman-Fogel, I., Yarnitsky, D. and Coghill, R.C. (2014) Distinct Brain Mechanisms Support Spatial vs. Temporal Filtering of Nociceptive Information. Pain, 155, 2491-2501. https://doi.org/10.1016/j.pain.2014.07.008

[32] Taylor, D.M. (1999) Inactivation of Prions by Physical and Chemical Means. Journal of Hospital Infection, 43, S69-S76. https://doi.org/10.1016/S0195-6701(99)90067-1

[33] Honigman, L., Yarnitsky, D., Sprecher, E. and Weissman-Fogel, I. (2013) Psychophysical Testing of Spatial and Temporal Dimensions of Endogenous Analgesia: Conditioned Pain Modulation and Offset Analgesia. Experimental Brain Research, 228, 493-501. https://doi.org/10.1007/s00221-013-3580-7

[34] Hermans, L., Calders, P., Van Oosterwijck, J., Verschelde, E., Bertel, E. and Meeus, M. (2016) An Overview of Offset Analgesia and the Comparison with Conditioned Pain Modulation: A Systematic Literature Review. Pain Physician, 19, 307-326.

[35] Kennedy, D.L., Kemp, H.I., Ridout, D., Yarnitsky, D. and Rice, A.S.C. (2016) Reliability of Conditioned Pain Modulation: A Systematic Review. Pain, 157, 2410-2419. https://doi.org/10.1097/j.pain.0000000000000689

[36] Niesters, M., Dahan, A., Swartjes, M., Noppers, I., Fillingim, R.B., Aarts, L. and Sarton, E.Y. (2011) Effect of Ketamine on Endogenous Pain Modulation in Healthy Volunteers. Pain, 152, 656-663. https://doi.org/10.1016/j.pain.2010.12.015

[37] Niesters, M., Hoitsma, E., Sarton, E., Aarts, L. and Dahan, A. (2011) Offset Analgesia in Neuropathic Pain Patients and Effect of Treatment with Morphine and Ketamine. Anesthesiology, 115, 1063-1071. https://doi.org/10.1097/ALN.0b013e31822fd03a

[38] Martucci, K.T., Eisenach, J.C., Tong, C. and Coghill, R.C. (2012) Opioid Independent Mechanisms Supporting Offset Analgesia and Temporal Sharpening of Nociceptive Information. Pain, 153, 1232-1243. https://doi.org/10.1016/j.pain.2012.02.035

[39] Martucci, K.T., Yelle, M.D. and Coghill, R.C. (2012) Differential Effects of Experimental Central Sensitization on the Time-Course and Magnitude of Offset Analgesia. Pain, 153, 463-472. https://doi.org/10.1016/j.pain.2011.11.010 


\section{Appendix 1. Ethical Committee Approval}

\section{THUS NOTEPAPER MUST NOT BE USED FOR}

SJH/AMNCH Research Ethics Committec Secretari Claire Hartin Ph: 414219

cmail: claire.hartin@amnch.ie

Dr. Deborah Galvin

Pain Special Interest Registrar

Tallaght Hospital

Tallaght

Dublin 24

11th October 2016

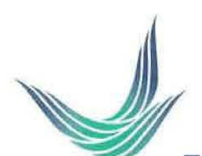

THE ADELAIDE \& MEATH HOSPITAL, DUBLIN

INCORPORATING

THE NATIONAL CHILDREN'S HOSPITAL

TALLAGHT, DUBUIN 24, IRELAND

TELEPHONE +353 14142000

Re: Agnikarma therapy (thermal eautery) as an adjunctive therapy to standard care for patients with knee osteoarthritis

REC Reference: 2016-10 Chairman's Action (3)

(Please quote reference on all correspondence)

Dear Dr. Galvin,

The REC is in receipt of your recent request to SJH/AMNCH Research Ethics Committee in which you queried ethical approval for the above named study.

The Chairman, Dr. Peter Lavin, on behalf of the Research Ethics Committee, has reviewed your correspondence and granted ethical approval for this study.

Yours sincerely,

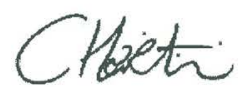

Claire Hartin

Secretary

SJH/AMNCH Research Ethics Committee

The SJH/AMNCH Joint Research and Ethics Committee operates in compliance with and is constituted in accordance with the European Communities (Clinical Trials on Medicinal Products for Human Use) Regulations 2004 \& ICH GCP guidelines. 


\section{Appendix 2. WHO 3-Step Analgesic Step Ladder}

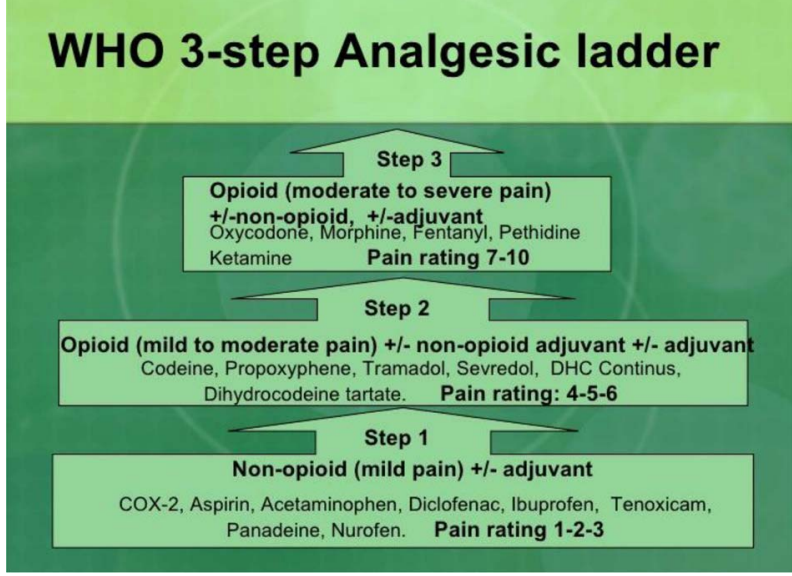

\section{Appendix 3. Patient Leaflet Template}

\section{PARTICIPANT INFORMATION LEAFLET}

\section{HOSPITAL: AMNCH}

\section{DEPARTMENT: Dept of Pain Medicine}

STUDY TITLE: Agnikarma therapy (thermal cautery) as an adjunctive therapy to standard care for patients with knee osteoarthritis

\section{NAME OF PRINCIPAL INVESTIGATORS:}

Dr Camillus Power- Consultant Pain Physician

Mr John Quinlan- Consultant Orthopaedic Surgeon

Dr Deborah Galvin- Pain Medicine Registrar

Dr Kazim Raza- Pain Medicine Registrar

You are being invited to participate in a research study. Thank you for taking time to read this.

\section{WHAT IS THE PURPOSE OF THE STUDY?}

We aim to measure the reduction in knee pain due to osteoarthritis in our patients after receiving Agnikarma therapy.

We will measure a reduction in pain by establishing a reduction in the amount of pain-killers taken by the patient.

We will also ask the patient if the find certain activities of daily living (eg dressing, walking up stairs, shopping) are easier to perform (due to improved pain) after Agnikarma treatment.

\section{WHY HAVE I BEEN CHOSEN TO PARTAKE IN THIS STUDY?}

You have been chosen as you are on a waiting list for a knee replacement (under Mr Quinlan's care). This study will not prevent you from getting a knee replacement, you will remain on the waiting list. 
WHAT WILL HAPPEN IF I VOLUNTEER TO PARTICIAPTE?

You will be contacted by a member of the team (either Dr Deborah Galvin or Dr Kazim Raza).

We will go through a pre-therapy questionnaire regarding the severity of pain you have, amount of pain killers you take, what types of pain killers and the difficulty you have doing daily activities (dressing, walking, showering etc)

You will be invited to visit the official website for this therapy: www.globalagnikarma.com

If you are happy to proceed, you will be given a date and time for attendance to our Out-patients where you will meet Dr Power, Consultant Pain Physician.

Any further questions you have we will be happy to answer them the morning of the procedure.

We will ask you to sign a study consent form and a separate procedure consent form.

The Agnikarma therapy will then be performed. This is a very short procedure and you will go home the same day.

\section{ARE THERE ANY RISKS INVOLVED IN PARTICIPATING?}

There is a small risk of skin irritation. If this happens, we will advise you to stop applying the cream and to start taking antihistamines.

\section{ARE THERE ANY BENIFITS INVOLVED IN PARTICIPATING?}

A potential reduction in pain of your painful knees.

WHAT HAPPENS IF I DO NOT AGREE TO PARTICIPATE? 
We fully understand if you do not wish to participate in the study. You will still remain on Mr Quinlan's waiting list for a knee replacement.

WILL MY PARTICIPATION OR WITHDRAWEL HAVE ANY IMPACT ON MY ROUTINE CARE?

Absolutely not

WILL MY PARTICIPATION BE CONFIDENTIAL?

Yes, all data will be anonymised.

\section{INDEMNITY}

Your doctors are insured by the State Claims Insurance Service.

$\begin{array}{lllll}\text { WHO IS ORGANISING AND FUNDING THIS } & \end{array}$ RESEARCH?

Department of Pain Medicine, Tallaght Hospital

HAS THIS STUDY REVIEWED BY AN ETHICS COMMITTEE?

Yes

CONTACT DETAILS

Name: $\quad$ Dr Deborah Galvin

Address: Dept of Pain Medicine, AMNCH, Tallaght, Dublin 24

Phone: $\quad 01-4143104$ 
Appendix 4. Consent Form

Version ..., date....

\section{PATIENT CONSENT FORM}

\section{PLEASE TICK YOUR RESPONSE IN THE APPROPRIATE BOX}

$\square \quad$ I have read and understood the Participant Information

YES · NO .

$\square \quad$ I have had the opportunity to ask questions and discuss the study

YES - NO .

$\square \quad$ I have received satisfactory answers to all my questions

YES · NO •

$\square$ I have received enough information about this study

YES - NO •

$\square$ I understand that I am free to withdraw from the study at any time without giving a reason and without this affecting my future medical care

YES - NO •

$\square \quad$ I agree to take part in the study

YES · NO •

Participant's Signature:

Date:

Participant's Name in print:

Investigator's Signature:

Date:

Investigator's Name in print: 